\title{
Uso de fotoprotetores na prevenção de danos por exposição solar: conceitos, avaliação histórica e recomendações
}

Os raios ultravioletas (UV) são elementos fundamentais para a vida humana, pois é através da exposição direta a eles que o organismo consegue sintetizar 80 a $90 \%$ da vitamina D necessária, no entanto, a exposição exacerbada a estes elementos pode acarretar danos permanentes à pele. Percebe-se que o uso de protetor solar ou fotoprotetor é algo indiscutível e vem ganhando mais espaço no mercado mundial. A elaboração de produtos com segurança e eficácia se baseia na compreensão de seu mecanismo de ação e formulações, sendo o Fator de proteção Solar (FPS) o principal dado para quantificação da eficácia fotoprotetora. Este estudo trata-se de uma revisão bibliográfica sobre fotoprotetores que tem por objetivo realizar uma revisão dos conceitos históricos que envolvem o uso de fotoprotetores, apresentando suas classificações quanto aos filtros UV e métodos de avaliação da proteção solar, evidenciando a importância do uso dos mesmos na prevenção contra danos cutâneos. O método de revisão de literatura baseou-se em artigos da língua portuguesa sobre fotoprotetores, danos da exposição solar e avaliação de filtros solares, disponíveis nos bancos de dados Periódicos Capes, Microsoft Academic Search, Biblioteca Virtual em Saúde e SCiELO (Scientific Eletronic Library Online). Findada a pesquisa, pode-se concluir que existem diversas apresentações de fotoprotetores e que seu uso correto é parte fundamental para uma tez saudável e sem danos.

\section{Use of photoprotectors to prevent damage by sun exposure: concepts, historical evaluation and recommendations}

Ultraviolet rays (UV) are fundamental elements for human life, because it is through direct exposure to them that the body can synthesize 80 to $90 \%$ of the necessary vitamin $D$, however, the exacerbated exposure to these elements can cause permanent damage to skin. It is perceived that the use of sunscreen or photoprotector is undeniable and has been gaining more space in the world market. The production of products with safety and efficacy is based on the understanding of their mechanism of action and formulations, with the Sun Protection Factor (SPF) being the main data to quantify the photoprotective efficacy This study is a bibliographic review on photoprotectors that aims to review the historical concepts that involve the use of photoprotectors, presenting their classifications regarding UV filters and methods of assessing sun protection, highlighting the importance of using them in preventing skin damage. The literature review method was based on articles in the Portuguese language about photoprotectors, damage from sun exposure and evaluation of sunscreens, available in the Capes Periodic databases, Microsoft Academic Search, Virtual Health Library and SciELO (Scientific Eletronic Library Online ). After the research, it can be concluded that there are several presentations of photoprotectors and that their correct use is a fundamental part for a healthy and harmless complexion.

Keywords: Ultraviolet rays; Sun protection factor; SPF composition.

Topic: Engenharia Biomédica e Biomedicina

Reviewed anonymously in the process of blind peer.
Received: 30/04/2021

Approved: 15/05/2021
Pollyanna Tavares de Lira Camelo (10

Instituto de Excelência em Educação e Saúde, Brasil

http://lattes.cnpq.br/1295573545941174

https://orcid.org/0000-0002-6696-2005

pollyanna_tavares@yahoo.com.br

Raygoria Cabral Sales Kellermanni

Instituto de Excelência em Educação e Saúde, Brasil

http://lattes.cnpq.br/6098899074657565

raygoria@yahoo.com.br
Referencing this:

CAMELO, P. T. L.; KELLERMANNI, R. C. S.. Uso de fotoprotetores na prevenção de danos por exposição solar: conceitos, avaliação histórica e recomendações. Scire Salutis, v.11, n.2, p.171-180, 2021. DOI: http://doi.org/10.6008/CBPC2236-9600.2021.002.0020 


\section{INTRODUÇÃO}

Os raios solares são indispensáveis para a vida humana, pois além de aquecer, é através da exposição direta a essa radiação que o organismo humano consegue sintetizar 80 a $90 \%$ da vitamina $D$, necessária para regulação da fisiologia osteomineral, sistema imunológico e cardiovascular (CASTRO, 2011).

Em 2007, Sgarb e colaboradores avaliaram que, considerando o tempo e a forma de exposição aos raios ultravioleta (UV), obtêm-se resultados distintos na pele, o que os levou a concluir que a exposição frequente e em baixas doses aos raios UV, resulta numa predisposição ao surgimento de carcinogênese. Por outro lado, a exposição aguda a estes, causam prejuízos à integridade tecidual, gerando inflamação, ulceração e consequente perda da barreira epidérmica (SGARB et al., 2007).

Tendo conhecimento da radiação emitida pelo sol e avaliando os riscos da exposição sem a devida proteção, desde o final do século XIX já se tem relato do uso de produtos como meio de se proteger, visando evitar queimaduras e o escurecimento cutâneo (SILVA et al., 2015).

$\mathrm{Na}$ década de 70, os produtos de fotoproteção ganharam espaço no mercado, com a proposta que o filtro solar deveria proteger a pele, evitando lesões celulares a curto e longo prazo, sendo essa proteção chamada de Fator de Proteção Solar (FPS) (SCHALKA et al., 2011).

Atualmente, existe uma gama extensa de filtros solares disponíveis no meio comercial e podem vir apresentados nas mais distintas formas (loções, cremes, mousse, etc.). Apesar de tanta informação disponível, grande parte da população desconhece a real função do fotoprotetor, o que acaba por gerar uma dúvida: como escolher o melhor produto e o que ele deve conter?

Para elucidar essa questão, o ideal seria que todo indivíduo pudesse ter o acompanhamento de um profissional dermatologista, de modo que, as necessidades da pele pudessem ser levadas em consideração na hora da escolha do produto de uso diário, no entanto, essa não é uma possibilidade real da sociedade, o que justifica a elaboração deste trabalho.

Nesse contexto, o objetivo deste artigo é apresentar, através de revisão bibliográfica, informações históricas sobre o uso do protetor solar, simplificando ao leitor o entendimento de sua composição e formas de apresentação, orientando quanto o uso correto de fotoprotetores, dando ênfase na importância do seu uso cotidiano a fim de evitar danos a curto e longo prazo.

\section{METODOLOGIA}

O presente trabalho consiste numa pesquisa bibliográfica, que é o desenvolvimento do estudo a partir de materiais já publicados em determinadas fontes como livros, textos, teses e dissertações, constituindo o procedimento básico para artigos e monografias (CERVO et al., 2002).

Nessa modalidade de escrita se busca o domínio teórico sobre determinado tema, de modo que, para que se exista uma pesquisa, é necessário que a priori, exista uma pergunta ou um questionamento que se deseje sanar, levando a conclusão de que pesquisar é buscar respostas para algo (CERVO et al., 2002).

Dos critérios de seleção para elaboração do presente, foram analisados documentos da língua 
portuguesa que contivessem informações sobre fotoprotetor, sua composição, apresentação, mecanismo de ação e as vantagens do uso diário, bem como a ação dos raios ultravioleta na pele.

Nos bancos de dados para pesquisa cientifica Periódicos Capes, Microsoft Academic Search, Biblioteca virtual em Saúde e SciELO (Scientific Eletronic Library Online), foram utilizados os descritos Fator de Proteção Solar, Raios Ultravioleta, Danos da exposição solar e Composição de Fotoprotetores, e localizados 45 artigos, dos quais 18 foram excluídos por não se enquadrarem nos critérios de seleção, restando 27 que serviram de base para este artigo.

\section{DISCUSSÃO TEÓRICA}

\section{Radiação solar e raios ultravioletas}

Para que se torne clara a necessidade do uso do protetor solar faz-se indispensável à compreensão sobre a ação da radiação solar ou radiação ultravioleta no organismo. O ser humano carece da energia solar para sobreviver, sendo seus efeitos no organismo dependentes de características individuais da pele de cada individuo exposto, da intensidade, frequência e tempo de exposição, sendo influenciados por fatores como localização geográfica, período do dia, estação do ano e condições climáticas (CHORILLI et al., 2007).

Grande fonte de calor, a radiação solar apresenta diversos benefícios na qualidade de vida da população, sendo responsável pela síntese de vitamina $D$ através da conversão de ergosterol, estímulo da produção de melanina, tratamento de icterícia e gerando uma sensação de bem estar físico e emocional, no entanto, é entendido que a radiação solar pode gerar prejuízos a saúde do organismo, caso as doses de exposição excedam o recomendado ou não sejam utilizadas com cautela (SILVA et al., 2015).

Sobre a Radiação UV, Rondon (2004) explica que:

As radiações ultravioletas são ondas eletromagnéticas emitidas pelo sol e se classificam de acordo com o seu comprimento em UVC (100-280 nm), UVB (280-315 nm) e UVA (315$400 \mathrm{~nm}$ ). Penetram diferentemente na pele de acordo com seu comprimento [...] quando o DNA da célula recebe radiação UV, a proteína P53 localizada no núcleo da célula é ativada a fim de reparar os danos causados, porém, quando esses danos são numerosos essa proteína dispara apoptose através da mitocôndria.

Como supracitado, o sol emite três tipos de raios invisíveis que atingem a atmosfera, podendo essa faixa de radiação ser dividida conforme o comprimento de onda em: UVA (315 a $400 \mathrm{~nm}$ ): representa 95\% da radiação solar na superfície terrestre, possui baixa capacidade de causar eritema - capacidade mil vezes menor que do raio UVB - no entanto, penetra mais profundamente da derme, atingindo fibras de colágeno e elastina, causando a liberação de radicais livres e consequente foto envelhecimento (CHORILLI et al.; 2007); UVB (280 a $315 \mathrm{~nm}$ ): representa apenas $5 \%$ da radiação solar que atravessa a atmosfera, apesar disso, possui grande energia radioativa, sendo frequentemente responsável por eritema (queimaduras). É capaz de induzir o estímulo de melanina, resultando em bronzeamento, conversão de ergosterol em vitamina $D$, tendo seu pico de emissão entre $10 \mathrm{~h}$ e $14 \mathrm{~h}$. A exposição frequente causa danos irreversíveis ao DNA celular, aumentando o risco de câncer de pele (CHORILLI et al., 2007); UVC (100 A 280 nm): apesar de portadora da energia mais lesiva aos seres humanos, não consegue chegar à superfície terrestre devido sua absorção pela camada de ozônio. Através de fontes artificiais e graças a sua propriedade bactericida, é 
aplicada na esterilização de objetos, materiais cirúrgicos e em processo de tratamento de água (MAIO, 2011).

Flor et al. (2007) explicam a interação da radiação com a pele da seguinte forma:

A energia da radiação solar aumenta com a redução do comprimento de onda, assim, a radiação UV é a de menor comprimento, e consequentemente, a mais energética, ou seja, a mais propensa a induzir reações fotoquímicas. Outra consideração importante diz respeito à capacidade dessa radiação permear a estrutura da pele. A radiação UV de energia menor penetra mais profundamente na pele, ao atingir a derme, é responsável pelo foto envelhecimento.

Compreende-se assim que as radiações UV penetram na pele causando alterações no DNA e RNA, e de acordo ao comprimento de onda, adentram mais profundamente interagindo em diferentes camadas, causando mutações em proteínas e genes, ou levando a apoptose (morte celular programada) (GODOY, et al., 2013).

\section{Breve história do uso do protetor solar}

O uso de barreiras contra os raios solares não é algo novo, desde a antiguidade, a pele pálida era associada a classes mais altas da sociedade e a pele bronzeada atribuída a trabalhadores manuais, já se utilizavam chapéus, sombrinhas e luvas como forma de proteção (CHORILLI et al., 2007).

Após o término da Primeira Guerra Mundial (1914-1918), houve uma mudança nos valores culturais, o que antes era sinônimo de riqueza passou a ser associado a pessoas que ficavam em ambientes fechados, como trabalhadores de escritórios e fábricas, deixando-os sem tempo para a exposição solar. Em contrapartida, os que tinham maior poder aquisitivo dispunham de tempo livre para usufruir de praias e campos (CHORILLI et al., 2007).

Já o uso de produtos fotoprotetores surgiu ainda no final do século XIX, no entanto, eram utilizadas substâncias muito limitadas e que pouco ofereciam proteção (SCHALKA et al., 2011). O quadro 1 apresenta uma visão cronológica sobre o uso de fotoprotetores e também sobre os primeiros ativos utilizados em sua composição.

Desde o início de sua utilização, o protetor solar tem como definição clássica ser um produto destinado ao bloqueio dos raios solares e proteção das células da pele contra efeitos nocivos da radiação ultravioleta, como queimaduras, hiperpigmentação e câncer de pele (SCHALKA, 2009).

Apesar de anteriormente ser pouco difundido na sociedade, atualmente existe uma vasta gama de produtos com diversos ativos, que, cumprindo funções específicas, além de proteger contra os raios UV ajudam numa melhor qualidade da pele.

No Brasil, a primeira marca de protetores a ser introduzida, ainda em 1984 , foi a Sundown ${ }^{\circledR}$ da empresa Johnson\&Johnson', que na época dispunha de foto protetores com FPS 4, 8 e 15, sendo responsável pelo conceito de FPS no mercado nacional, o que ajudou a propagar informação e sensibilização da necessidade da proteção contra radiação UV (SILVA, 2015). 
Quadro 1: Linha cronológica do uso de fotoprotetores e ativos utilizados na composição.

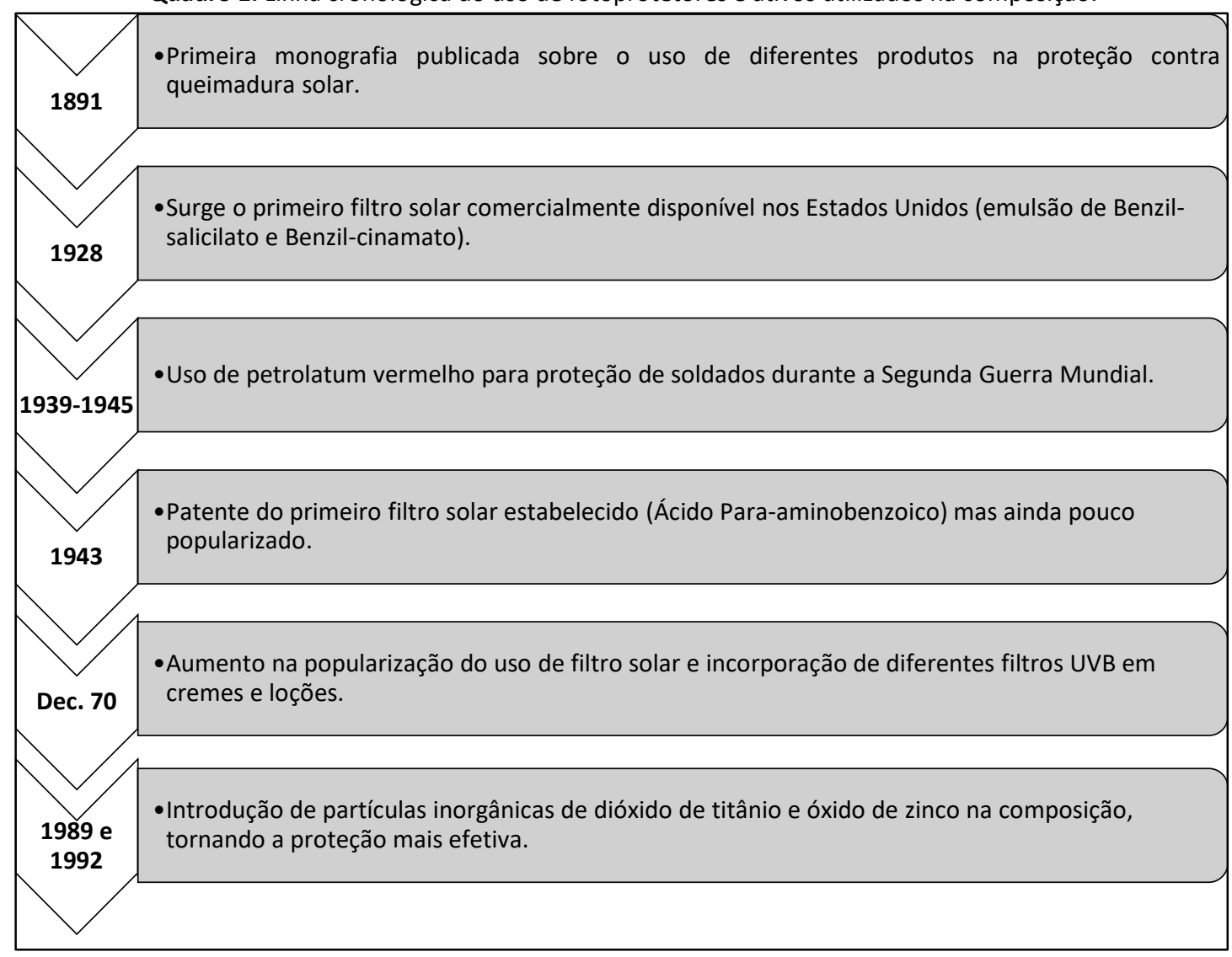

Fonte: Adaptado de Schalka et al. ( 2011).

\section{Filtro Ultravioleta: funcionamento}

Como menciona Schalka (2009), os protetores são compostos que ajudam a proteger a pele contra danos dos raios UV, contendo substâncias ativas capazes de dispersar, absorver ou refletir a radiação, evitando seus danos. Estas substâncias são chamadas de filtros ultravioletas ou filtros UV e podem ser divididas de acordo a suas características físico-químicas em filtros inorgânicos (físicos) ou orgânicos (químicos).

Os filtros UV orgânicos como o Ácido P-aminobenzóico (PABA), Salicilatos, Ésters de PABA e Benzopenonas são moléculas que interferem na radiação incidente por meio do mecanismo de absorção (CHORILI et al., 2007). Schalka e Reis (2011) salientam que:

O filtro atua como cromóforo exógeno ao absorver um photon de energia e evoluir para o estado excitado da molécula. Ao retornar para o estado estável (não excitado), ocorre à liberação de energia em um comprimento de onda mais longo, seja na faixa da luz visível (como fluorescência) seja na faixa da radiação infravermelha (como calor). [...] dependendo da capacidade de absorver comprimentos de onda mais longos ou mais curtos os filtros orgânicos podem ser subclassificados em filtros UVA, filtros UVB ou filtros de amplo espectro (UVA e UVB).

Os filtros inorgânicos por sua vez, geralmente são produtos de origem mineral como Dióxido de titânio, Óxido de zinco, Caulim e Silicato de magnésio, e possuem como mecanismo de ação a capacidade de refletir ou dispersar a radiação incidente. Estes compostos apresentam como principal característica a baixa permeação cutânea e elevada foto estabilidade, o que faz com que mantenham sua capacidade foto protetora mesmo após longos períodos de exposição à radiação UV (TEIXEIRA, 2016). 


\section{Legislação Brasileira e Apresentação do foto protetor}

A legislação Brasileira classifica os filtros solares como cosméticos de grau 2, ou seja, produtos com risco potencial que possuem indicações específicas, cuja características de segurança e eficácia devem ser comprovadas de acordo as normas vigentes (MINISTÉRIO DA SAÚDE, 2012).

Em concordância com a Lei 6360/1976, de 23 de Setembro de 1976, os produtos cosméticos - aos quais se enquadram os protetores - devem ser submetidos ao sistema de vigilância sanitária, regulamentados pelos Decretos 79.094/1977 e 83.239/1979 e complementadas por Resoluções da Diretoria Colegiada (RDC), onde, através de regulamentos técnicos, harmonizados no âmbito do MERCOSUL, adotarão definições, metodologias analíticas para determinação de FPS, substâncias permitidas e proibidas bem como suas concentrações, resistência à água, dizeres obrigatórios presentes nos rótulos e procedimentos para registro dos produtos. (BRASIL, 1976).

Da perspectiva médica, os produtos de foto proteção devem ter estabilidade, ou seja, a capacidade de manter as mesmas propriedades e características do momento de sua fabricação até o fim de sua vida útil, sendo não degradante, não irritante e compatível com aditivos e princípios ativos (ROCHA et al., 2010).

Para a formulação do protetor solar é necessário dois componentes básicos: o veículo e os ingredientes ativos (filtros orgânicos e/ou físicos). Quanto aos meios de apresentação, envolvem desde simples soluções á estruturas mais complexas como emulsões, que variam de acordo a necessidade e característica da pele de cada indivíduo, sendo as principais, conforme discorre Cabral et al. (2013): Bloqueador solar: indicado para peles mais claras e sensíveis ao sol ou para pessoas que possuam alguma patologia cutânea, uma vez que neutralizam os raios UV e impedem que cheguem á epiderme; Soluções hidro alcoólicas: compostas principalmente de água e álcool, são fáceis de espalhar na pele e evaporam rapidamente, no entanto, o efeito do álcool etílico sobre a pele representa um ponto negativo em sua utilização; Cremes e loções emulsionadas: constituídas de componentes hidrossolúveis e lipossolúveis, podem ser apresentados na forma O/A (óleo em água) ou A/O (água em óleo), sendo as preparações $\mathrm{A} / \mathrm{O}$ mais saudáveis para pele, no entanto, de aspecto mais gorduroso, sendo indicado para pessoas com pele seca ou mista, devido seu poder hidratante; Géis: obtidos através de espessantes hidrofílicos, geralmente não oferecem os mesmos níveis de proteção que as emulsões. Indicados geralmente para pessoas com pele oleosa, por ser uma formulação que substitui óleo por água, deixando-a mais leve; Spray: produtos de fácil aplicação e geralmente de alta resistência a água e ao suor, pela adição de polímeros formadores de película, ou emulsificantes insolúveis em água fria. São indicados para pessoas que praticam esportes; Fotoproteção oral: age em nível celular ou molecular, diminuindo os danos gerados após a exposição solar. Pode ser composto por ativos isolados ou associados, sendo mais conhecidas a vitamina $\mathrm{C}$ e E, os carotenóides e polifenóis.

Existem ainda roupas, chapéus, luvas, maquiagens, máscaras de tratamento, produtos cosméticos, acessórios, dentre outros, que podem vir acrescidos de foto proteção, devendo ser avaliados pelos mesmos critérios e respeitando as mesmas diretrizes que os protetores comuns. 


\section{FPS: O Fator de Proteção Solar}

Em 1934, Friedrich Ellinger fez o primeiro relato da avaliação da eficácia dos protetores solares, determinando a dose eritematosa mínima na pele protegida e não protegida, através da exposição dos dois antebraços a lâmpada de mercúrio, propondo um coeficiente de proteção decrescente à medida que a proteção aumentava (FLOR et al., 2007).

No ano de 1956 houve outra inovação em relação ao FPS, quando Rudolf Schulze propôs a avaliação in vivo dos foto protetores disponíveis no mercado através do cálculo de um fator de proteção em que se dividia o tempo de exposição necessário para indução de eritema com o protetor, pelo tempo necessário para produção sem protetor utilizando doses de radiação progressiva emitidas por lâmpadas com espectro de radiação mais próximo da luz solar (COELHO, 2005).

O resultado obtido pelo experimento de Schulze ficou conhecido como "Fator Schulze" que recebeu nova denominação em 1974 por Greiter, tornando-se mundialmente conhecido como Fator de Proteção Solar (FPS), título que perdura atualmente (SILVA, 2015).

Somente em 1978, a agência regulatória norte-americana FDA propôs a primeira normatização para determinação do FPS, sendo definido como a razão numérica entre a Dose Eritematosa Mínima (DEM) da pele protegida com a quantidade de $2 \mathrm{mg} / \mathrm{cm}^{2}$ de certo protetor, e a Dose Mínima da pele não protegida, sendo apresentada conforme seguinte equação matemática (SILVA et al., 2015):

FPS $=\frac{\text { DEM (Pele com protetor solar) }}{\text { DEM (Pele sem protetor solar) }}$

Conforme o proposto pelo FDA em 1978, para determinação in vivo do valor do FPS são selecionados um grupo de 10 a 20 voluntários de foto tipo I a III (classificação de Fitzpatrick) que serão submetidos a doses progressivas de radiação UV emitidas por um simulador de luz solar (fonte artificial), em regiões da pele não protegidas e protegidas pelo protetor solar em estudo em quantidade de $2 \mathrm{mg} / \mathrm{cm}^{2}$. (FERREIRA et al., 2011).

A leitura da Dose Eritematosa Mínima nas duas áreas é realizada após $16 \mathrm{~h}$ à $24 \mathrm{~h}$ da exposição de modo que, a média dos valores encontrados representa o Fator de Proteção Solar do produto avaliado (FERREIRA et al., 2011).

Baseado nesse estudo pode-se compreender que o FPS indica o tempo permitido de exposição ao sol após aplicação do protetor. Simplificando, se o filtro solar tiver FPS 20, ele permite a exposição ao sol por um período 20 vezes maior do que se estivesse sem proteção obtendo-se o mesmo resultado.

A determinação do FPS também pode ser realizada in vitro, sendo calculada a partir de espectrofotometria, utilizando-se soluções diluídas que contém o filtro solar a ser avaliado (TEIXEIRA, 2016). O "método de Mansur" como ficou conhecido, foi desenvolvido em 1979 e apesar de oferecer uma metodologia simples, rápida e de baixo custo, não pode ser empregada na avaliação de foto protetores físicos devido à insolubilidade destes nos solventes mais utilizados, como o etanol (MORAES, 2006).

Por determinação da RDC $n^{\circ} 30$ de 1 de junho de 2012, os métodos preconizados para avaliação do 
FPS são métodos in vivo, podendo o método in vitro ser utilizado para avaliação prévia de produtos durante o processo de formulação, antes de ser encaminhado para testes em humanos (MINISTÉRIO DA SAÚDE, 2012).

\section{PPD (Persistent Pigment Darkening)}

A sigla PPD (Persistent Pigment Darkening em livre tradução Escurecimento Persistente do Pigmento), representa a proteção contra as radiações UVA, e se baseia na resposta de pigmentação tardia ou persistente frente à radiação UVA, sendo avaliado in vivo, em voluntários humanos (FERREIRA, 2011)

De modo semelhante à avaliação do FPS, o teste de PPD é realizado em um painel de pessoas expostas a luz UVA, sendo avaliado o tempo necessário para que sua pele bronzeie e comparando a área protegida e desprotegida. Seu nível ideal deve ser igual ou superior a 10 representando no mínimo 1/3 (um terço) do Fator de Proteção Solar (MELLO, 2015). Exemplo: em um Protetor solar com FPS 60, o PPD deve ser igual ou superior a 20 para uma proteção efetiva da pele, evitando lesões e distúrbios.

\section{Consequências de exposição solar sem proteção}

Já se sabe que a exposição excessiva a radiação ultravioleta acarreta em inúmeros danos, que podem se apresentar de forma imediata ou tardia. As lesões celulares resultam em alterações que vão desde hiperpigmentação por estímulo na produção de melanina a carcinomas (MIRANDA et al., 2016).

Como descreve Flor et al (2007), a pele humana possui três mecanismos naturais de defesa que consistem em: espessamento da camada córnea (parte mais superficial da pele), produção de melanina pelos melanócitos (escurecimento da região) e produção de ácido urônico (derivado da oxidação de uma aldose), porém, esses mecanismos de defesa não são suficientes dependendo do grau de exposição, tendo como consequência lesões. Pode-se ter uma ideia dos principais danos da exposição solar observando o quadro 2 .

Quadro 2: Danos da exposição solar sem o uso de foto proteção.

\begin{tabular}{|c|c|c|}
\hline TIPO DE LESÃO & APRESENTAÇÃO & TRATAMENTO \\
\hline Queimadura solar & $\begin{array}{l}\text { Vermelhidão na pele, dor e ardência, seguida ou não do } \\
\text { surgimento de bolhas. } \\
\text { Em casos de insolação, o indivíduo pode apresentar dor de } \\
\text { cabeça, vômito e diarreia. }\end{array}$ & $\begin{array}{l}\text { Aumentar a ingestão hídrica. Utilizar cremes e loções } \\
\text { calmantes em regiões de pele íntegra e, em caso de febre ou } \\
\text { surgimento de bolhas, procurar atendimento médico. }\end{array}$ \\
\hline $\begin{array}{l}\text { Foto } \\
\text { envelhecimento }\end{array}$ & $\begin{array}{l}\text { Aparecimento de rugas, melanose solar, espessamento do } \\
\text { extrato córneo e aspereza. }\end{array}$ & $\begin{array}{l}\text { Uso de cosméticos, peeling, eletroterapia, luz intensa } \\
\text { pulsada, tratamento a laser fracionado, terapia fotodinâmica } \\
\text { e aplicação de toxinas e preenchedores. }\end{array}$ \\
\hline $\begin{array}{l}\text { Problemas de } \\
\text { visão }\end{array}$ & $\begin{array}{l}\text { Visão embaçada, tremor nos olhos, dificuldade de se } \\
\text { adaptar a luz, olhos vermelhos e lacrimejando, perda de } \\
\text { visão. }\end{array}$ & $\begin{array}{l}\text { Tratamento cirúrgico ou medicamentoso indicado por } \\
\text { especialista. }\end{array}$ \\
\hline Acne & $\begin{array}{l}\text { Inchaço do orifício onde a secreção sebácea é excretada, } \\
\text { causando seu acúmulo. }\end{array}$ & $\begin{array}{l}\text { Rotina de cuidados com a pele que incluem uso de filtro solar } \\
\text { oil free, higienização com sabonetes específicos para pele } \\
\text { acneica e uso de produtos com ação anti-inflamatória e } \\
\text { secativa. }\end{array}$ \\
\hline Melasma & $\begin{array}{l}\text { Escurecimento de regiões expostas ao sol, com manchas de } \\
\text { aspecto irregular de tom em variações de castanho. }\end{array}$ & $\begin{array}{l}\text { O uso de cremes clareadores a base de ácidos, aplicação de } \\
\text { peeling e é indispensável o uso do foto protetor. Não tem } \\
\text { cura e seu tratamento deve ser contínuo a fim de evitar o } \\
\text { reaparecimento das manchas. }\end{array}$ \\
\hline $\begin{array}{l}\text { Queratose ou } \\
\text { ceratose actínica }\end{array}$ & $\begin{array}{l}\text { Aparecimento de lesões avermelhadas e ásperas } \\
\text { frequentemente no rosto, lábios, orelhas, braços, colo e } \\
\text { couro cabeludo, sendo mais palpáveis que visíveis. }\end{array}$ & $\begin{array}{l}\text { O tratamento geralmente é feito com uso de medicamentos } \\
\text { tópicos, criocirurgia, laser, peeling químico e terapia } \\
\text { fotodinâmica. }\end{array}$ \\
\hline
\end{tabular}




\begin{tabular}{|l|l|l|}
\hline Câncer de pele & $\begin{array}{l}\text { Existe uma diversidade de cânceres de pele. Apresentam-se } \\
\text { geralmente com lesões na pele de aparência elevada, pintas } \\
\text { que mudam de cor e textura ou aumentam de tamanho } \\
\text { com bordas irregulares, manchas ou feridas que não } \\
\text { cicatrizam além de outros sintomas. }\end{array}$ & $\begin{array}{l}\text { Ao surgimento de quaisquer sintoma, o médico deve ser } \\
\text { imediatamente procurado, sendo o tratamento escolhido de } \\
\text { acordo a necessidade e evolução do quadro carcinogênico, } \\
\text { podendo variar entre: cirurgia excisional, curetagem e } \\
\text { eletrodissecção, criocirugia, cirurgia a laser, etc. }\end{array}$ \\
\hline
\end{tabular}

Fonte: adaptado de Sociedade Brasileira de Dermatologia (2011).

Todas as alterações citadas no quadro 2 podem ser evitadas com o uso correto do protetor solar, e acessórios que também contenham fotoproteção, como óculos, chapéus e roupas, sendo seu uso indispensável inclusive durante o tratamento. O câncer de pele é o distúrbio de maior relevância, pois se comparado aos demais, é o que apresenta maiores índices de mortalidade.

O Instituto Nacional do Câncer (INCA) estima que, no ano de 2020, 176.939 novos casos de câncer de pele sejam diagnosticados no Brasil, destes, 88.770 sejam em homens e 93.160 em mulheres. Comparando-se ao estimado no ano de 2014, que era de 182.130 novos casos, observa-se uma redução, apesar da previsão de que este tipo de câncer continuará sendo o mais incidente no Brasil, país que apresenta o maior índice de raios ultravioleta (MINISTÉRIO DA SAÚDE, 2020).

Os dados institucionais justificam a preocupação das autoridades para a questão da foto proteção, pois é a forma mais efetiva de prevenção contra danos dos raios UV. Ressalta-se ainda que, além do sol, fontes artificiais também são capazes de emitir raios ultravioletas, o que torna ainda mais imprescindível o uso diário e correto do foto protetor.

Outro ponto relevante a ser avaliado é a frequência do uso dos protetores e a quantidade correta a ser aplicada para uma proteção efetiva. A conscientização sobre o uso do protetor solar é indispensável para a obtenção de bons resultados tanto na prevenção contra queimaduras e lesões malignas, quanto no tratamento estético.

Em 2011, a Sociedade Brasileira de Dermatologia (SBD) constatou em uma análise populacional que $59 \%$ dos entrevistados se expõe a luz solar sem qualquer proteção. No estudo também se observou que grande parte dos homens (79\%) não faz uso de qualquer proteção enquanto 45,16\% das mulheres alegaram não usar, o que confirma os resultados obtidos de que os homens se cuidam menos que as mulheres (SOCIEDADE BRASILEIRA DE DERMATOLOGIA, 2011).

Didier et al. (2014) realizaram um estudo transversal com 398 estudantes regularmente matriculados em uma instituição de ensino superior privada, onde puderam concluir que da amostra estudada $45,2 \%$ relatou o uso diário do foto protetor e $82,4 \%$ relatou o uso do produto em caso de exposição voluntária ao sol. 0 estudo também expôs que as mulheres referiam o uso de foto protetores em situações de exposição voluntária ou não - com maior frequência, se comparado aos homens, levando a crer que se preocupam mais com a proteção da pele.

O uso inadequado ou insuficiente do protetor pode ser atribuído à falta de informação de muitos, pensando nisso, a SBD elaborou o primeiro Consenso de Foto proteção no Brasil, que traz as recomendações sobre o uso do protetor voltadas para o clima brasileiro e esclarece também a importância da educação em foto proteção, desde a infância até a idade adulta (SOCIEDADE BRASILEIRA DE DERMATOLOGIA, 2013). 


\section{Recomendações quanto ao uso do foto protetor}

Para que se tenha uma proteção efetiva contra os danos dos raios UV é preciso seguir algumas recomendações (SOCIEDADE BRASILEIRA DE DERMATOLOGIA, 2013): Sobre a escolha do produto: é importante consultar um dermatologista para que se escolha o melhor produto para cada tipo de pele e necessidade. Escolher protetores que protejam tanto de raios UVA quanto de UVB é imprescindível; Sobre a qualidade de aplicação: aplicar o produto 20 a 30 minutos antes da exposição ao sol, tempo necessário para formar um filme homogêneo sobre a pele e garantir a proteção desejada; Sobre a quantidade a ser aplicada: especialistas indicam a medida da colher de chá - rosto (medida de 1 colher), tronco - frente e costas (medida de duas colheres), cada braço (medida de uma colher) e cada perna (medida de duas colheres); Sobre a reaplicação: o filtro solar deve ser reaplicado a cada duas ou três horas, após imersão em água ou intensa sudorese.

Vale ressaltar que a proteção contra raios UV não deve se ater apenas a pele; os olhos, fibra capilar e lábios são igualmente importantes para a saúde. O uso de produtos pós-sol é uma recomendação válida para minimizar as agressões provocadas pela radiação.

\section{CONCLUSÕES}

Com a realização do presente, infere-se que, o uso do protetor solar é a forma mais eficaz de prevenção contra danos e lesões a nível celular, sendo necessária a aplicação em quantidades suficientes para cobertura da região a ser protegida e sua reaplicação após 2 horas de exposição.

Existem no Brasil legislações específicas que determinam os filtros UV permitidos e suas concentrações seguras, visando à redução da toxicidade do produto e aumentando sua ação protetora. Entende-se ainda que, a exposição solar direta, ou seja, sem foto proteção, deve ocorrer em horários onde a radiação na superfície terrestre é menor. Essa exposição deve ocorrer de forma suficiente para que aconteça a síntese de vitamina D, mas sem exposição ao risco de lesões. Fora destes horários, o uso do filtro solar é essencial para uma cútis sem danos.

A conscientização do populacional sobre a importância do uso de protetor ou bloqueador solar e sua correta utilização é parte fundamental para obtenção de uma pele saudável, reduzindo os índices de câncer de pele e demais patologias relacionadas à exposição solar desprotegida, bem como para se obter sucesso em tratamentos estéticos e patológicos.

\section{REFERÊNCIAS}

BRASIL. Lei no 6.360. Dispõe sobre a Vigilância Sanitária a que ficam sujeitos os Medicamentos, as Drogas, os Insumos Farmacêuticos e Correlatos, Cosméticos, Saneantes e Outros Produtos, e dá outras Providências. Brasília: DOU, 1976.

BRASIL. Câncer de pele não melanoma. INCA, 2020.

BRASIL. Regulamento Técnico Mercosul sobre Protetores Solares em Cosméticos. Brasília: Agencia nacional de vigilância sanitária, 2012.
CABRAL, L. D.; PEREIRA, S. O., PARTATA, A. K.. Filtros solares e fotoprotetores: uma revisão. Infarma Ciências Farmacêuticas, v.25, n.2, p.108-110, 2013.

CASTRO, L. C.. O sistema endocrinológico vitamina D. Arq Bras Endocrinol Metab, v.55, n.8, p.566-575, 2011.

CERVO, A. L.; BERVIAN, P. A.. Metodologia cientifica. 5 ed. Sao Paulo: Prentice Hall, 2002.

CHORILLI, M., OTTO, T., ALVES, M. I., CAVALLINI, M. E. LEONARDI, G. R.. Avaliação do uso de protetores solares pela 
população rural de Piracicaba - São Paulo - Brasil, através da aplicação de questionário. Revista Brasileira de Farmácia, v.4, n.88, p.167-172, 2007.

COELHO, L. C.. Protetor solar: desenvolvimento farmacotécnico e avaliação de eficácia e segurança. Dissertação (Mestrado em Ciências Farmacêuticas) Universidade Federal de Pernambuco. Recife, 2005.

DIDIER, F. B.; BRUM, L. F.; AERTS, D. R.. Hábitos de exposição ao sol e uso de fotoproteção entre estudantes universitários de Teresina-Piauí. Revista Epidemiol. Serv. Saúde, v.23, n.3, p.45, 2014.

FERREIRA, G. C.; FERNANDES, C. M.; \& FERRARI, M.. Uso correto de fotoprotetor: quantidade aplicada, hábitos de exposição e de aplicação do produto. Revista Brasileira de Farmácia, v.92, n.3, p.191-197, 2011.

FLOR, J.; DAVOLOS, M. R.; CORREA, M. A.. Protetores solares. Revista Química Nova, p.23-28, 2007.

FONSECA, J. J.. Metodologia de pesquisa cientifica. Universidade Estadual do Ceara, 2002.

GODOY, A. S., SANTOS, L. M., GRIGNOLI, C. R., SIMIONATO, M. I.; GRIGNOLI, L. C.. Relação do uso do protetor solar com a incidência do câncer de pele. Revista Científica da UNIARARAS, v.1, n.2, p.65-73, 2013.

MAIO, M.. Tratado de Medicina Estética. 2 ed. São Paulo: Roca, 2011

MELLO, L. D.. A relação dos consumidores com o protetor solar. Belo Horizonte: Universidade FUMEC, 2015.

MIRANDA, P. T., MOREIRA, J. A.. Fotoproteção, revisão literária dois tipos e risco do não uso. Revista Cientifica da FHO-UNIARARAS, v.4, n.1, p.68-73, 2016.

MORAES, R. R., ARAUJO, J. E.; MOITA, G. C.. Avaliação do fator de proteção solar (fps) de protetores solares comerciais por espectrofotometria. In: CONGRESSO BRASILEIRO DE QUIMICA, 46. Anais. Salvador, 2006.
ROCHA, L. I., PEREIRA, C. S.; CARDOSO, M. A.. Elaboração de uma formulação inovadora de base facial com filtro solar uva e uvb. In: ENCONTRO LATINO AMERICANO DE INICIAÇÃO CIENTífICA, 14. Anais. Universidade do Vale do Paraíba, 2010.

RONDON, A. S.. Efeitos da radiação ultravioleta na pele. São Paulo: Copyringht Jr., 2004.

SCHALKA, S.. Influencia da quantidade aplicada de protetores solares no fator de proteção solar (FPS): avaliação de dois protetores com os mesmos ingredientes em diferentes concentrações. São Paulo: Universidade de São Paulo, 2004.

SCHALKA, S.; REIS, V. M.. Fator de Proteção Solar: significado e controvérsias. Anais Brasileiro Dermatologia, v.86, n.3, p. 507-515, 2011

SGARB, F. C., CARMO, E. D.; ROSA, L. E.. Radiação Ultravioleta e Carcinogenese. Revista de ciências médicas, v.16, n.4, p.245-250, 2007.

SILVA, R. R., MACHADO, P. F., ROCHA, R. J., \& SILVA, S. C. A.. Luz e os Filtros Solares: uma temática sociocientífica. Revista Virtual de Química, v.7, n.1, p.218-241, 2014.

SBD. Cuidados Diários com a Pele. Sociedade Brasileira de Dermatologia, 2020

SBD. Fotoproteção no Brasil: recomendações da Sociedade Brasileira de Dermatologia. Sociedade Brasileira de Dermatologia, 2013.

TARTUCE, T. J.. Métodos de pesquisa. Fortaleza: UNICE, 2006.

TEIXEIRA, M. S.. Avaliação da Atividade Fotoprotetora de Formulação Cosmética Contendo Associação entre Fração em Clorofórmio de Garcinia Carbogia Desr. e filtro sintético de amplo espectro. Dissertação (Mestrado em Ciências Farmacêuticas) - Universidade Federal de Juiz de Fora, Juiz de Fora, 2016

A CBPC - Companhia Brasileira de Produção Científica (CNPJ: 11.221.422/0001-03) detém os direitos materiais desta publicação. Os direitos referem-se à publicação do trabalho em qualquer parte do mundo, incluindo os direitos às renovações, expansões e disseminações da contribuição, bem como outros direitos subsidiários. Todos os trabalhos publicados eletronicamente poderão posteriormente ser publicados em coletâneas impressas sob coordenação da Sustenere Publishing, da Companhia Brasileira de Produção Científica e seus parceiros autorizados. Os (as) autores (as) preservam os direitos autorais, mas não têm permissão para a publicação da contribuição em outro meio, impresso ou digital, em português ou em tradução. 